\title{
Intrathecal bombesin-induced inhibition of gastrointestinal transit: requirement for an intact pituitary-adrenal axis
}

\author{
Randy J. Koslo ${ }^{\mathrm{b}}$, Debra E. Gmerek ${ }^{\mathrm{c}}$, Alan Cowan ${ }^{\mathrm{d}}$ and Frank Porreca ${ }^{\mathrm{a}}$ \\ a Department of Pharmacology, The University of Arizona Health Sciences Center, Tucson, AZ 85724 , \\ ${ }^{\circ}$ Bristol-Myers Products, Hillside, NJ 07207, 'University of Michigan Medical School, Ann Arbor, \\ MI 48109, and ${ }^{\mathrm{d}}$ Temple University School of Medicine, Philadelphia, PA 19140, U.S.A.
}

(Received 22 August 1985; revised manuscript received and accepted 14 February 1986)

\section{Summary}

The role of the pituitary-adrenal axis in the inhibition of gastrointestinal transit caused by intrathecal administration of bombesin was examined. Bombesin (0.3-10 $\mu \mathrm{g}$ ) slowed transit by this route in a dose-related manner. Either hypophysectomy or adrenalectomy prevented the inhibition of gastrointestinal transit associated with bombesin $(10 \mu \mathrm{g}$, i.th.). The inhibitory gut effects of this peptide were not prevented in sham-operated rats. Intrathecal bombesin-induced inhibition of gastrointestinal transit is thus dependent upon an intact pituitary-adrenal axis.

bombesin; intrathecal; gastrointestinal transit; adrenalectomy; hypophysectomy

\section{Introduction}

Bombesin is a tetradecapeptide originally isolated from amphibian skin; subsequently, homologues of this peptide were found to be located in the brain, gut and skin of mammals. Centrally administered bombesin produces poikilothermia [1], hyperglycemia [2], satiety [3], and elicits excessive grooming [4] in the rat. Additionally, centrally given bombesin has potent gastrointestinal effects; these include a doserelated inhibition of gastrointestinal transit when bombesin is administered by either

Correspondence and present address: Frank Porreca, Ph.D., Department of Pharmacology, The University of Arizona Health Sciences Center, Tucson, AZ 85724, U.S.A. Phone: (602) 626-7421. 
i.c.v. [5] or i.th. [6] routes, stimulation of gastric mucus production [7] and inhibition of gastric acid secretion [8].

In a previous study [9], we established that the inhibitory gastrointestinal transit effect of i.c.v. bombesin was dependent upon an intact pituitary-adrenal axis. Although it has previously been demonstrated that both i.c.v. [5] and i.th. [6] bombesin is effective in inhibiting transit, the recent recognition of the spinal cord as a target site for gastrointestinal drugs [10] and subsequent demonstration of independent modulation of gut function at spinal or supraspinal levels [11] suggest that these effects may be mediated through two discrete pathways. Thus, the dependence of i.c.v. bombesin gut effects on an intact adrenal-pituitary axis need not necessarily apply to the effects of the i.th. peptide. In the present study, we investigated the possibility that the inhibitory gastrointestinal transit effects of $i . t h$. bombesin may be mediated through the pituitary-adrenal axis. We found that both the pituitary and the adrenal glands are necessary for i.th. bombesin to inhibit transit. Therefore, the inhibition of gastrointestinal transit by i.th. bombesin appears to share a common pathway with i.c.v. bombesin, which is dependent on an intact pituitary and adrenal system.

\section{Materials and Methods}

\section{Animals and housing}

Hypophysectomized, adrenalectomized and appropriate sham-operated, male Sprague-Dawley rats (60-75 g, Charles River), were obtained 4 days post-surgery along with normal, unoperated counterparts. All animals were allowed 3 days to acclimatize after delivery, during which time the hypophysectomized rats and their sham controls were given $5 \%$ glucose $(\mathrm{w} / \mathrm{v})$ in the drinking water; the adrenalectomized rats and their sham controls were given $0.9 \% \mathrm{NaCl}(\mathrm{w} / \mathrm{v})$ in the drinking water. These dietary supplements were included to help maintain the viability of the postoperative animals. Normal rats received ordinary tap water. Animals were kept in a temperature controlled room with a standard 12-h light/dark cycle. Food was available ad libitum, except for the 16 -h period immediately prior to the gastrointestinal transit experiments.

\section{Measurement of gastrointestinal transit}

Gastrointestinal transit was measured as previously described [12]. Animals were starved overnight. Each rat received a single i.th. injection of either saline or bombesin followed immediately by an oral injection of ${ }^{51} \mathrm{Cr}$ as sodium chromate in saline $(0.5 \mu \mathrm{Ci}, 0.2 \mathrm{ml} / \mathrm{rat})$ (ICN Corporation). $35 \mathrm{~min}$ after administration of the marker, the animal was killed by cervical dislocation and the stomach and small bowel excised. The small intestine was placed on a ruled template and divided into 10 segments of equal length. The stomach and each of the 10 intestinal segments were placed into individual and consecutive culture tubes and the radioactivity in each tube was determined by gamma counting for one min. Transit of the marker along the intestine was calculated using the geometric center (G.C.) method [13]. Geometric centers 
range from a low of 1.0 (all radioactivity located in the first segment) to a high of 10 (transit of all radioactivity to the most distal segment). A minimum of five rats were used at each dose. Statistical analyses of the transit data were performed using the ANOVA followed by Student's $t$-test for unpaired data.

\section{Injections and compound}

Intrathecal injections were made at the lumbar L5-L6 level of unanesthetized rats. A constant 5- $\mu$ l volume was injected using a Hamilton microliter syringe fitted with a 30 gauge needle as described by Hylden and Wilcox [15]. Bombesin (Peninsula Laboratories) was made up in distilled water and frozen in aliquots until immediately prior to use.

\section{Results}

Bombesin administered i.th. (0.3-10 $\mu \mathrm{g} / \mathrm{rat})$ significantly delayed gastrointestinal transit in a dose-related fashion in normal rats (Fig. 1). The highest dose of bombesin (10 $\mu \mathrm{g} / \mathrm{rat}$ ) was given i.th. to hypophysectomized, adrenalectomized and appropriate sham-operated animals. As seen in Fig. 2, bombesin was still effective in inhibiting transit in both groups of sham-operated rats. There was no significant difference in results between sham animals and normal rats receiving the same test compound (saline or bombesin). In contrast, hypophysectomy or adrenalectomy eliminated the inhibition of transit caused by i.th. bombesin (Fig. 3). The basal level of transit in the hypophysectomized or adrenalectomized rats, measured after i.th. saline, was not
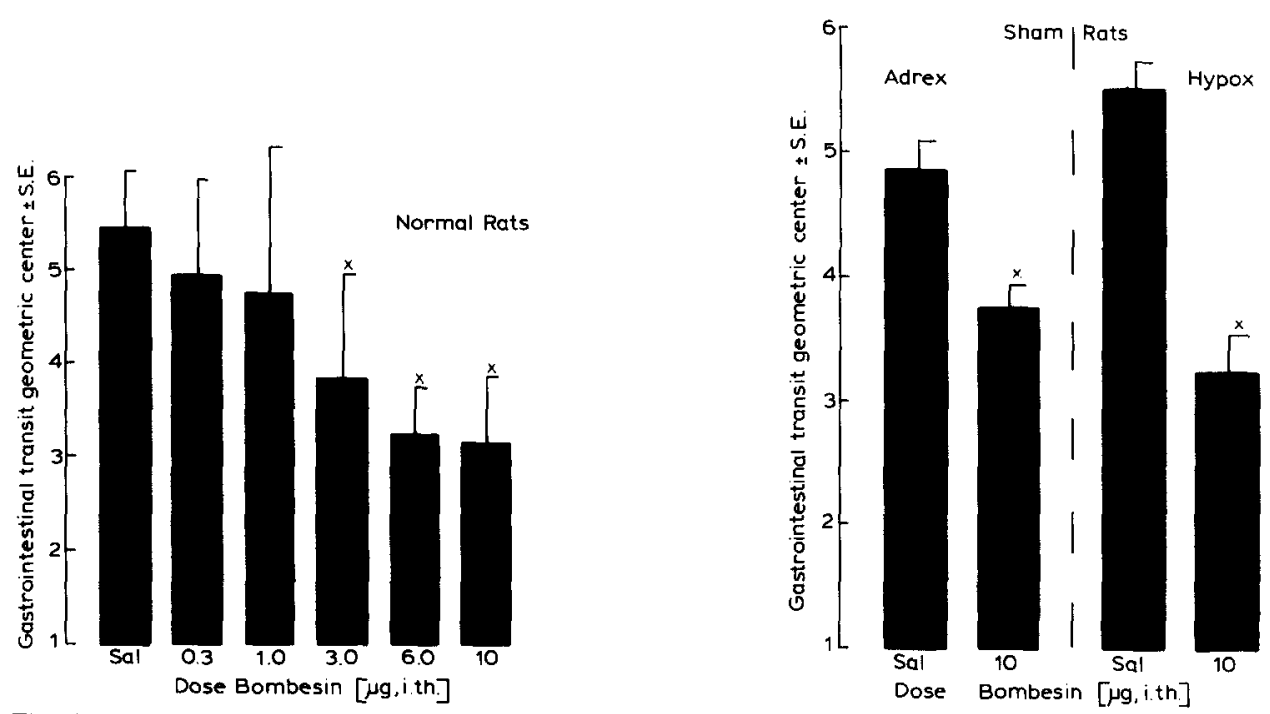

Fig. 1. Dose-response relationship for i.th. bombesin inhibition of gastrointestinal transit in the rat. Graded doses of bombesin were given concurrently with oral sodium chromate/saline and transit measured after $35 \mathrm{~min}$.

Fig. 2. Effects of i.th. bombesin $(10 \mu \mathrm{g})$ or saline on gastrointestinal transit in sham-operated rats. 


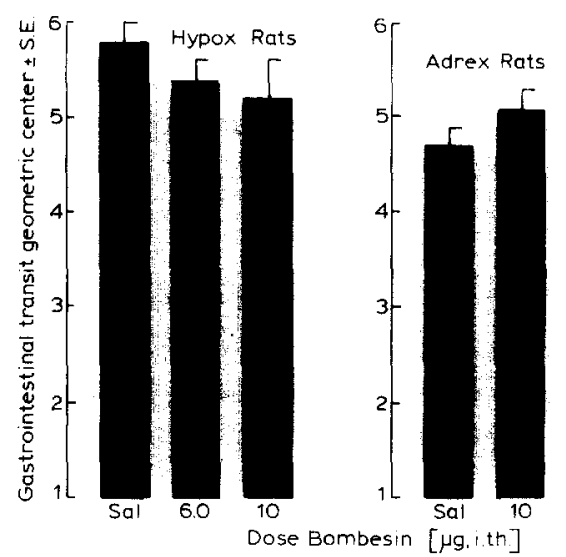

Fig. 3. Effects of i.th. bombesin (6 or $10 \mu \mathrm{g}$ ) or saline on gastrointestinal transit in hypophysectomized (Hypox) rats or i.th. bombesin (10 $\mu \mathrm{g})$ or saline on transit in adrenalectomized (Adrex) rats.

significantly different from normal rats or sham-operated animals. The response at each dose of compound was determined using $8-12$ rats.

\section{Discussion}

Intrathecal administration of bombesin inhibited gastrointestinal transit in a dose-related manner in agreement with our previous work [6]. This effect of the i.th. peptide was eliminated by either hypophysectomy or adrenalectomy, in agreement with previous results with i.c.v. bombesin [9]. Thus, i.c.v. and i.th. bombesin appear to produce their antitransit effects via a common pathway involving the pituitaryadrenal axis. Recently, we demonstrated that an intact brain-cord pathway was necessary for manifestation of the gastrointestinal antitransit effects of i.th. bombesin in the mouse; cord transection abolished the gut effects of the i.th. peptide [15]. In light of those data, it seems possible that the i.th. bombesin-induced inhibition of transit in rats operates through an ascending pathway to supraspinal centers where the pituitary influence of the adrenal glands becomes a necessary link in the chain of events leading to slowing of gut transit.

Previous work has shown that the synthesis of epinephrine in the adrenal medulla is controlled by the pituitary [16]. Hypophysectomy results in a marked reduction of phenylethanolamine- $N$-methyltransferase (PNMT), the enzyme catalyzing the final step of epinephrine synthesis; the activity of PNMT is dependent on the levels of circulating adrenocorticotropic hormone (ACTH) which may indirectly stimulate the activity of this enzyme via adrenal glucocorticoids. It has recently been demonstrated that ACTH is effective in increasing adrenal medullary PNMT activity in neonatal rats (i.e. 7 days old) indicating that the pituitary-adrenal axis has been established at a young age [17]. As hypophysectomy effectively decreases epinephrine content $[16,18]$, it seems possible, then, that the hypophysectomized animals in our experiments already had markedly reduced amounts of epinephrine in the adrenal medulla. 
Effectively, these hypophysectomized animals may have been functionally the same as the adrenalectomized group. Thus, i.th. bombesin may rely on the release of epinephrine from the adrenal medulla in order to produce its inhibitory effects on gastrointestinal transit. This centrally initiated effect appears to be via activation of a supraspinal site, resulting in subsequent alteration of gut motility via either a neural or humoral pathway. In this regard i.c.v. administration of bombesin was shown to inhibit gastric emptying, an effect which was abolished by subdiaphragmatic vagotomy in the rat [5]. The present study, however, showed that hypophysectomy or adrenalectomy also eliminated the inhibitory effects of bombesin $(10 \mu \mathrm{g}$, i.th.) on gastric emptying (data not shown). This suggests the possibility of a feedback loop to vagal centers by the endocrine system or perhaps dual control of gastric emptying by hormonal and neural inputs initiated by centrally given bombesin. It is not known if this concept could apply to the intestinal antitransit effects of i.c.v. or i.th. bombesin. It seems possible, however, that bombesin-stimulated release of hormones from the pituitary could act on the adrenals to influence transit.

Interestingly, bombesin-induced scratching and grooming behavior was not significantly influenced by either adrenalectomy or hypophysectomy after i.c.v. [4] or i.th. administration ([6] and this study). This is also true for the inhibition of gastric acid secretion by centrally given bombesin [8]. Adrenalectomy eliminates the hyperglycemia [2] and increases gastric mucus production associated with central administration of bombesin. Thus, this peptide exerts its myriad effects through numerous pathways. The exact mechanism by which i.th. bombesin influences gastrointestinal activity remains unclear at the present time.

\section{Acknowledgment}

This work was supported by USPHS Grant NS-21193 (F.P.).

\section{References}

1 Tache, Y., Pittman, Q. and Brown, M., Bombesin induced poikilothermy in rats, Brain Res., 188 (1980) 525-530.

2 Brown, M.R., Rivier, J. and Vale, W.W., Bombesin affects the central nervous system to produce hyperglycemia in rats, Life Sci., 21 (1977) 1729-1734.

3 Gibbs, J., Kulkosky, P.J. and Smith, G.P., Effects of peripheral and central bombesin on feeding behavior in rats, Peptides, 2 (Suppl. 2) (1981) 179-183.

4 Gmerek, D.E. and Cowan, A., Studies on bombesin-induced grooming in rats, Peptides, 4 (1983) 907-913.

5 Porreca, F. and Burks, T.F., Centrally administered bombesin affects gastric emptying and small and large bowel transit in the rat, Gastroenterology, 85 (1983) 313-317.

6 Gmerek, D.E., Cowan, A. and Vaught, J.L., Intrathecal bombesin in rats: effects on behavior and gastrointestinal transit, Eur. J. Pharmacol., 94 (1983) 141-143.

7 Tache, Y., Bombesin: central nervous system action to increase gastric mucus in rats, Gastroenterology, 83 (1982) 75-80.

8 Tache, Y., Vale, W., Rivier, J. and Brown, M., Brain regulation of gastric secretion: influence of neuropeptides, Proc. Natl. Acad. Sci. USA, 77 (1980) 5515-5519. 
9 Gmerek, D.E. and Cowan, A., Pituitary-adrenal mediation of bombesin-induced inhibition of gastrointestinal transit in rats, Regul. Peptides, 9 (1984) 299-304.

10 Porreca, F., Filla, A. and Burks, T.F., Spinal cord mediated opiate effects on gastrointestinal transit in mice, Eur. J. Pharmacol., 86 (1982) 135-136.

11 Porreca, F., Mosberg, H.I., Hurst, R., Hruby, V. and Burks, T.F., Roles of mu, delta and kappa opioid receptors in spinal and supraspinal mediation of gastrointestinal effects and hot-plate analgesia in the mouse, J. Pharmacol. Exp. Ther., 230 (1984) 341-348.

12 Porreca, F. and Burks, T.F., The spinal cord as a site of opioid effects on gastrointestinal transit in the mouse, J. Pharmacol. Exp. Ther., 227 (1983) 22-27.

13 Miller, M.S., Galligan, J.J. and Burks, T.F., Accurate measurement of intestinal transit in the rat, J. Pharmacol. Meth., 6 (1981) 211-217.

14 Hylden, J.L.K. and Wilcox, G.L., Intrathecal morphine in mice: A new technique, Eur. J. Pharmacol., 67 (1980) 313-316.

15 Koslo, R.J., Burks, T.F. and Porreca, F., Centrally administered bombesin affects gastrointestinal transit and colonic bead expulsion through supraspinal mechanisms, J. Pharmacol. Exp. Ther., (1986) in press.

16 Wurtman, R.J. and Axelrod, J., Adrenaline synthesis: Control by the pituitary gland and adrenal glucocorheoids, Science, 150 (1965) 1464-1465.

17 Banerji, T.K., Callas, G., Meyer, W.J. and Rassoli, A., ACTH increases adrenal medullary PNMT activity in neonatal rats, Life Sci., 38 (1986) 343-349.

18 Brown, M.R. and Fisher, L.A., Brain peptide regulation of adrenal epinephrine secretion, Am. J. Physiol., 247 (1984) E4l-E46. 